\title{
Challenges and Strategies for Pakistan in the Third Wave of COVID-19: A Mini Review
}

\author{
Kashif Kamran $^{1 *}$ and Abid Ali ${ }^{2}$ \\ ${ }^{1}$ Department of Zoology, University of Balochistan, Quetta, Pakistan, ${ }^{2}$ Department of Zoology, Abdul Wali Khan University \\ Mardan, Khyber Pakhtunkhwa, Pakistan
}

The world is currently gripped by the fear of the corona virus disease 2019 (COVID-19) pandemic. The causative agent of COVID-19 is a novel coronavirus known as Severe Acute Respiratory Syndrome Coronavirus 2 (SARS-CoV-2) that attacks humans without prejudice, and primarily targets the respiratory system. Pakistan is a developing country with a large population and a weak economy. Currently, it is facing a major challenge to cope with the outbreak of the COVID-19 pandemic, especially the third wave. This fatal virus has increased its presence many folds in Pakistan. On average, 100 deaths per day were being recorded in the late spring of 2021. Delay in the acquisition of vaccine has

\section{OPEN ACCESS}

Edited by:

Andreia Silva Costa, ISAMB \& ESEL, Portugal

Reviewed by:

Radu Adrian Crisan Dabija, Grigore T. Popa University of Medicine

and Pharmacy, Romania Thang Van Vo,

Hue University, Vietnam

*Correspondence:

Kashif Kamran

kashifkamran944@gmail.com

Specialty section:

This article was submitted to Public Health Policy,

a section of the journal

Frontiers in Public Health

Received: 04 April 2021

Accepted: 07 June 2021

Published: 13 August 2021

Citation: Kamran K and Ali A (2021) Challenges and Strategies for Pakistan in the Third

Wave of COVID-19: A Mini Review.

Front. Public Health 9:690820.

doi: 10.3389/fpubh.2021.690820 slowed down the vaccination program for this disease. This in turn will accelerate the spreading of virus, and thus will lead to a lockdown situation.

Keywords: pandemic, COVID-19, outbreak, death, lockdown

\section{ORIGIN AND HISTORY OF COVID-19 IN PAKISTAN}

The first novel SARS-CoV-2 infected patient was reported in December 2019 (1), and the disease was shortly after named COVID-19 in January 2020 (2). The deadly disease has rapidly spread to around 215 countries since its origin from a seafood wholesale market in Wuhan, a central city in the People's Republic of China (PRC) (3). People would have never imagined that the situation shown in Steven Soderbergh's pandemic thriller movie Contagion (released in 2011) would become reality with the COIVD-19 pandemic (4). There has been considerable discussion on the multiple waves of this causative virus and its control measures.

Pakistan is an under-developed country with a population of about 220 million. It has five provinces: Balochistan, Sindh, Khyber Pakhtunkhwa (KPK), Punjab, and Gilgit Baltistan. The first case of COVID-19 was confirmed on 26th February 2020 by the Ministry of Health, Pakistan (5) and then a continuous spreading of this disease was observed across the country. This virus initially entered Pakistan through returning pilgrims from Iran (through the Taftan border), Saudi Arabia (6), and from Pakistanis who were trapped in other countries that were brought in on special flights (7). Pakistan is currently in a state of health emergency. A total of 1,024,737 tests were carried out with 672,931 (about 66\%) confirmed cases of COVID-19 and more than 14,530 (about 2.1\%) deaths, reported till late March 2021. Pakistan also experienced the recovery of 605,274 patients (about 90\%) and the number of currently reported patients that are under treatment in the health sector is $\sim 53,127$ (Figures 1, 2). According to available data, about 300 medical workers in Pakistan are among the fatal victims of COVID-19. The provincial government of Sindh province was the first to implement a full lockdown, due to which the spread of this virus was reduced to some extent. 


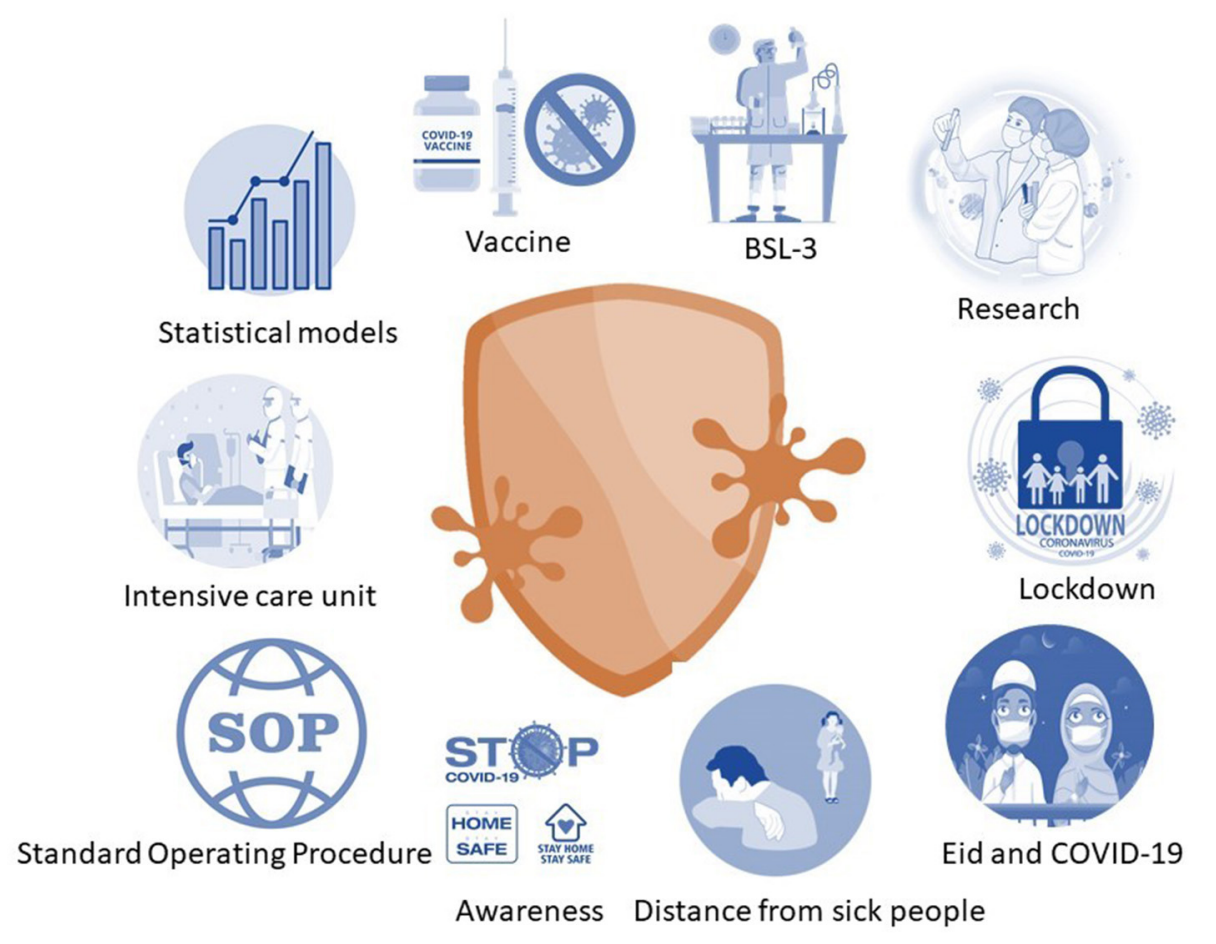

GRAPHICAL ABSTRACT | Possible potential approaches for decreasing the risks of COVID-19.

\section{FIRST AND SECOND WAVE OF COVID-19}

Since its eruption, the first wave of the disease was very uncertain due to the unknown nature of the virus, its mechanism of infectivity, transmission, and possible treatment options. However, the rapid response of every country, including Pakistan, controlled the fatal prevalence of COVID-19. During the initial wave, Pakistan was very successful in managing the transmission of the disease. It was made possible due to implementation of partial and smart lockdown policies. In partial lockdown, limited time for movement was allowed to citizens after which free movement was strictly prohibited. In smart lockdown, specific areas within a city were sealed where COVID19 positive cases were detected. Nevertheless, a second wave of the disease occurred, which was moderate in its transmission and pathogenicity. It could have been due to the progressive development in treatment and vaccinations.

\section{THE THIRD WAVE OF COVID-19}

WHO had already warned the Pakistani government that the number of people infected with COVID-19 could exceed 0.2 million by mid-July, 2020 (8). However, no such expected infection rate was reported. A new variant of SARS-CoV-2 (known as 20I/501Y.V1, VOC 202012/01, or B.1.1.7) emerged from the United Kingdom (9), and has been detected in over 64 countries as of January 27, 2021, including Pakistan (10). This B.1.1.7 variant is associated with an increased risk of death compared to other variants with average deaths of 100 patients reported on a daily basis in Pakistan. Due to the arrival of this new variant, the 10 cities of Pakistan, Bahawalpur, Faisalabad, Hyderabad, Islamabad, Lahore, Multan, Muzaffarabad, Peshawar, Rawalpindi, and Swat, were put under stiff lockdown till April 11,2021 , where the provincial administration was directed to observe the strict implementation of SOPs.

One thing that was very common between the first and third wave was the time of onset i.e., Spring (from March till end of April). It may lead to the generation of a hypothesis that pollens have a significant role in the enhanced transmission of SARS-CoV-2 virus.

\section{COVID-19 AND COMORBIDITIES}

It has been observed in several cases that COVID-19 patients develop certain additional comorbidities like typhoid, Myocarditis, blood coagulation, and the fatal attack of black fungus. The co-occurrence of these secondary disorders clearly indicate that SARS-CoV-2 provides a favorable condition for the growth of other microbes, however, its mechanism of action is still unexplored.

\section{DRUGS AND VACCINATION PROGRAMS}

As of June 17,2020, there was no vaccine available for COVID-19, but various drugs i.e., Tocilizumab, Bemsivir lyophilized, Ninavir lyophilized, Dexamethasone and Azithromycin, were used to 


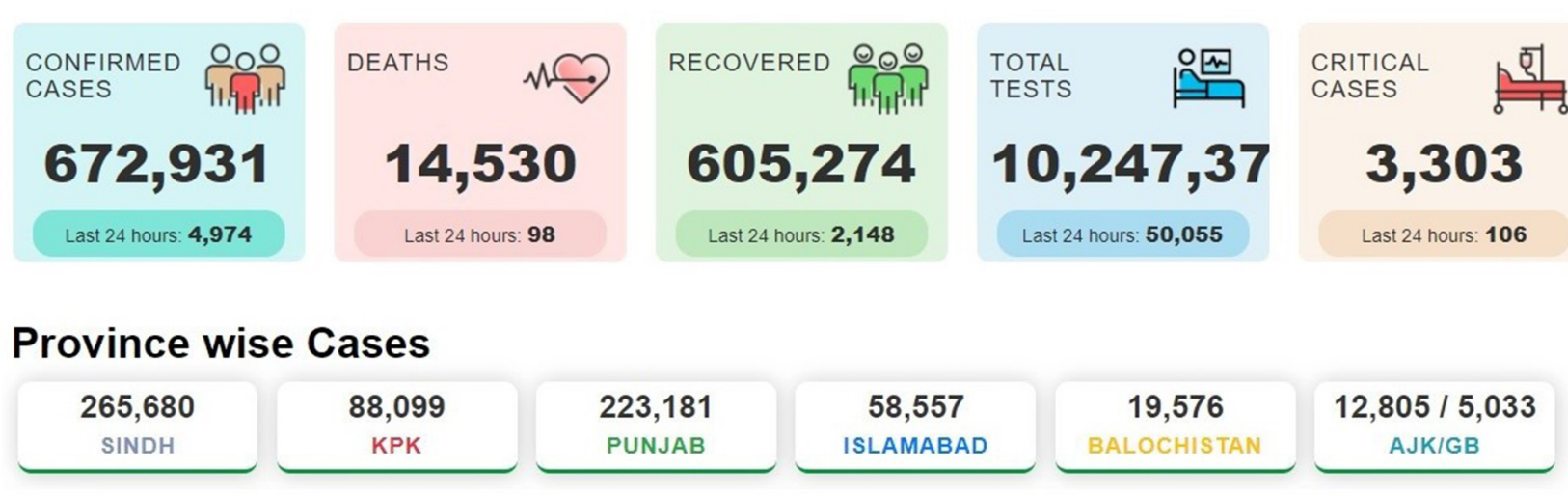

FIGURE 1 | COVID-19 status in Pakistan. The figure illustrates the deaths, confirmed cases, and tests performed from May 2020 to 31 st March 2021 (The data were obtained from https://covid.gov.pk/).

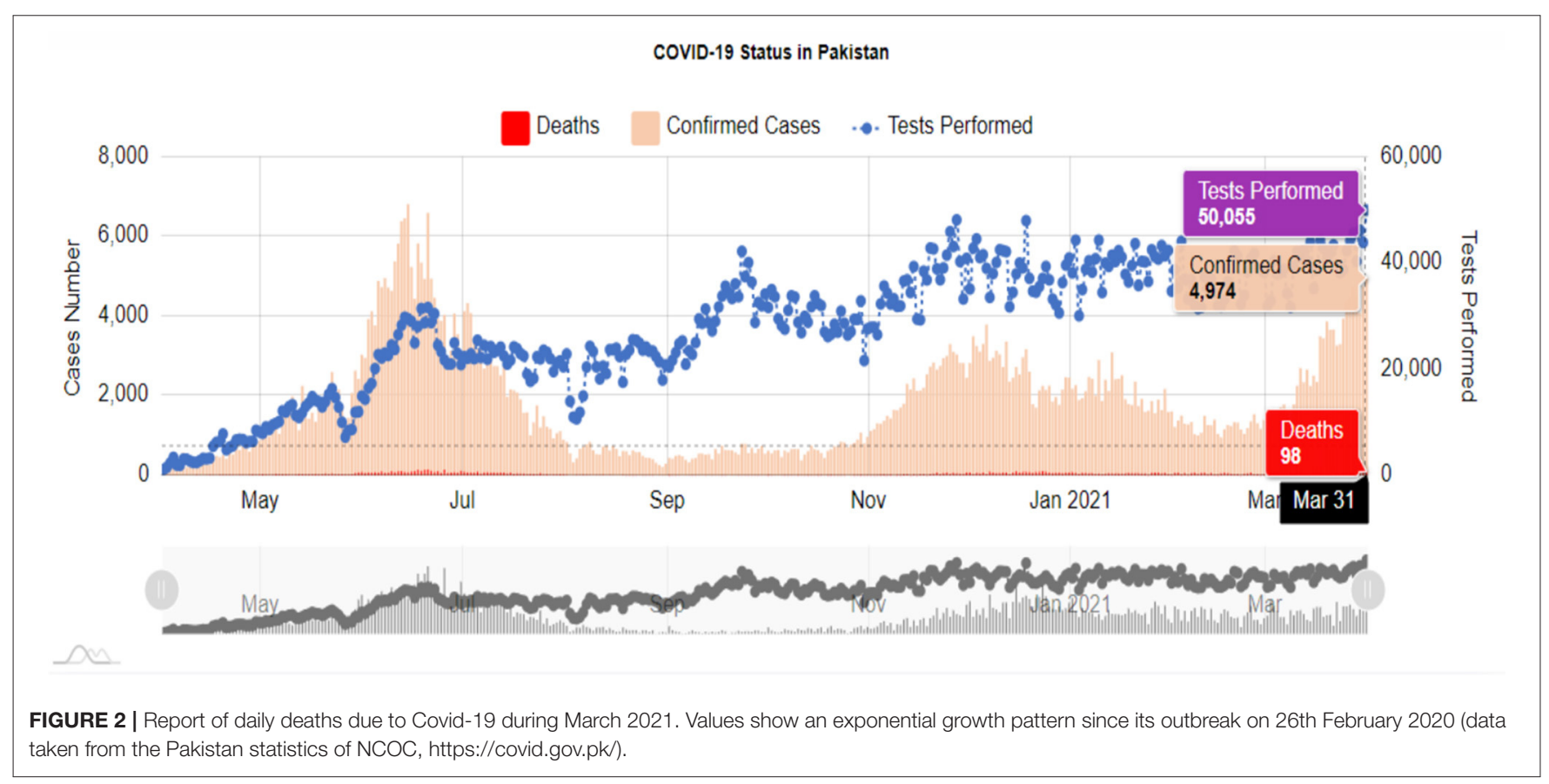

treat the disease without proper regulation. Therefore, the only way to stop the spread of the virus was to observe self-isolation and social distancing from other people. The Drug Regulatory Authority of Pakistan (DRAP), after taking into account the set standards of quality and safety, approved hydroxychloroquine as the first medicine to treat COVID-19 patients. Later on, convalescent plasma therapy was also approved for the treatment of seriously affected COVID-19 patients. Then, a combination of the drugs chloroquine and azithromycin was also found to be effective in clinical trials against COVID-19 (11). Tocilizumab, an anti-interleukin-6 receptor monoclonal antibody, was also successful in a trial at Agha Khan Hospital, Karachi, Pakistan (12), however this method was not adopted by the Federal Government as a possible treatment to cure COVID-19 patients.
Today, vaccines are widely used to protect millions of people around the world from various infectious diseases. Therefore, it was expected that this pandemic would be controlled after the development of a corona vaccine. In this hope, Russia announced the first relevant vaccine (SputnikV) within just 15 weeks of the outbreak of the corona virus (13). Presently, DRAP has approved the four most promising vaccines: CanSino (CanSinoBIO, China), Sinopharm (Sinopharm Group Co., Ltd, China), Sputnik-V (Gamaleya Research Institute of Epidemiology and Microbiology, Russia), and Oxford-AstraZeneca (a joint adventure of the University of Oxford and Vaccitech Limited, United Kingdom). The vaccine developed by Pfizer was not approved due to its extreme low preservation temperature (i.e., $-80^{\circ} \mathrm{C}$ ) as Pakistan lacks such 

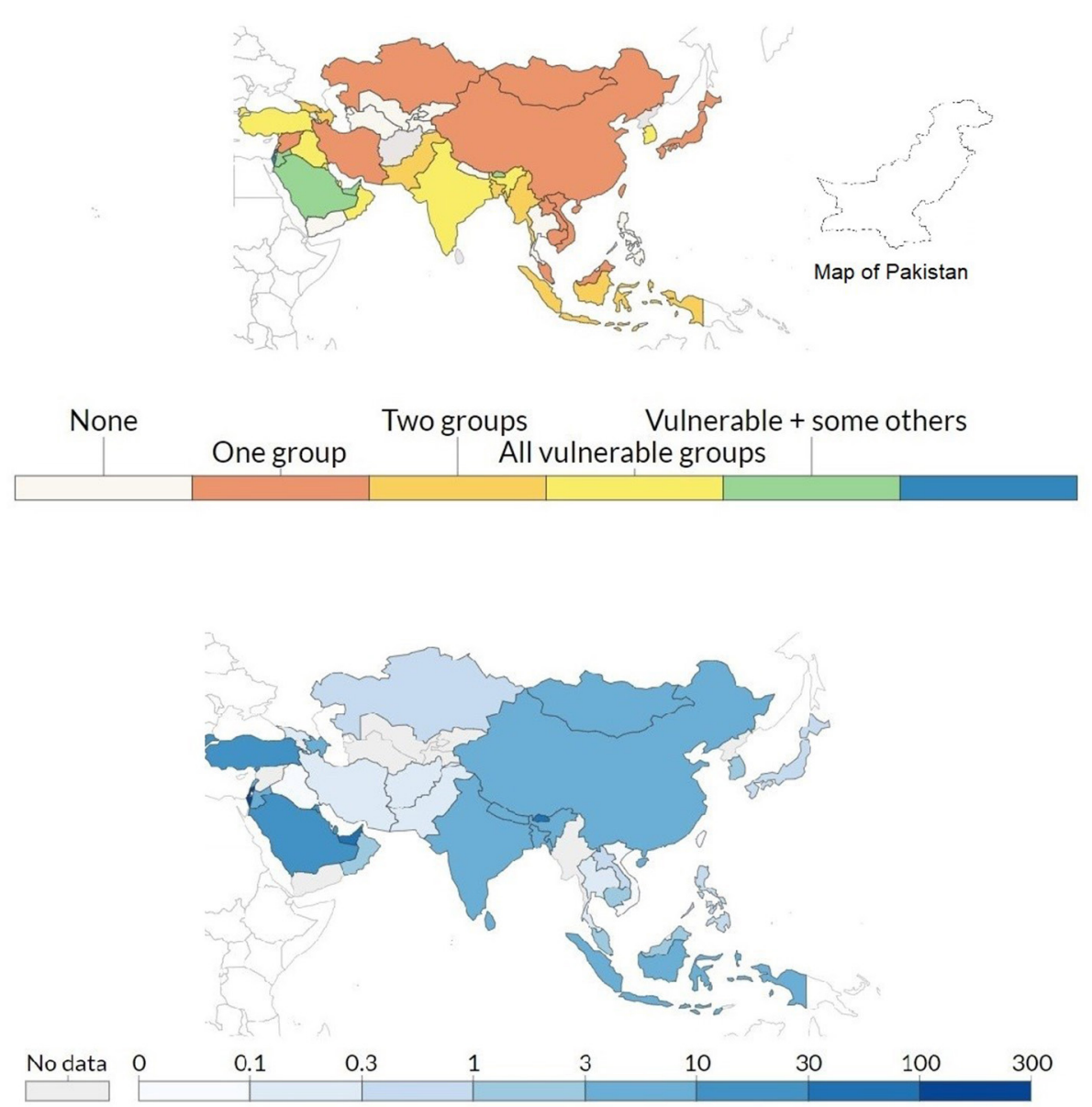

FIGURE 3 | Top: Metric records policies in Asian countries for vaccine delivery for three groups: (i) keyworkers, (ii) clinically vulnerable, and (iii) the elderly. Here one means to ensure the supply of the vaccine to one of the three groups, two means to ensure that two of three groups receive the vaccine, while three means ensuring that all groups receive the vaccine equally. Bottom: Metric record of the total number of vaccination doses administered per 100 people in the total population. This data counted as a single dose, even though people have received two doses of the vaccine (opensource: https://ourworldindata.org/).

facilities. The above stated four vaccines can be preserved around $0^{\circ} \mathrm{C}$, which is quite easy to manage. Pakistan had received a donation of 3 million vaccine doses by mid- April, 2021 from CanSino. Pakistan will also receive 17 million doses of OxfordAstraZeneca vaccine under the WHO-led COVAX program for developing countries (14). According to a Gallup Survey Poll of Pakistan, "Sixty percent of Pakistanis said that they would get the COVID-19 vaccine if it became available, whereas $34 \%$ respondent were worried about the side effects and $22 \%$ are against the vaccine" (15). The hallmarks of COVID-19 is that it has a higher mortality and pathogenicity in elderly people as compared to those younger than 18 (16). Currently, frontline health care workers and senior citizens (above 60 years) are receiving the Sinopharm vaccine (Figure 3) which consists of two doses and has been donated by China. The Federal Government has also issued licenses to pharmaceutical companies to purchase the Russian and Chinese vaccines and allowed them to sell to the private sector at a government approved price.

\section{FUNDAMENTAL CHALLENGES OF COVID-19 IN PAKISTAN}

The current pandemic was not treated in Pakistan in the same way as other countries. Earlier predictive models suggested that the onset of summer may reduce the severity of the virus. However, the results of recently conducted research on COVID19 does not support the earlier model and concluded that this virus is independent of weather conditions and climate change (17). A vast majority of the people did not follow the instructions and guidelines set by the Federal Government and subordinate departments (18) including the National Command Operation Center (NCOC), Ministry of Health, National Disaster Management Authority (NDMA), and the Drug Regulation Authority (DRA), which has resulted in the major spread of COVID-19 in Pakistan.

Despite various efforts made by NCOC to control COVID-19 transmission in Pakistan, some major shortcomings contributed 
to the deterioration of the corona situation. These include lack of public awareness at rural areas and a non-cooperative approach by the public toward free testing facilities provided by the government to avoid COIVD-19. The number of issues related to COVID-19 are continuously amplifying and getting more complicated each day, leading to the situation being seen as a catastrophic failure by the government (19).

\section{WORLD APPROACH DURING THE PANDEMIC}

During the pandemic, the world has learned some important lessons. The first lesson was that health, economy, and human development are interlinked. It is necessary that these parameters be connected to achieve UN sustainable development goals in a coordinated manner $(20,21)$. It should be emphasized that public health is not an individual or government matter but it is the overall responsibility of a society (22). The third key point is the importance of the development of telemedicine training courses (23), forensic training (24), and patient referral systems (25) for medical professionals and health workers. Most developed countries have developed several statistical evidence based decision-making systems (26) and this should also be extended to under-developed and non-developed countries. It was also observed that the health care system of America collapsed during corona the pandemic despite being the best health care systems in the world. Each country must improve their current ability to deal with emergencies under normal circumstances (27).

\section{POSSIBLE POTENTIAL SOLUTIONS}

The following strategic solutions are proposed to overcome the issue of COVID-19. These solutions are:

(i) Statistical model-based forecasting tools should be developed that may help in forecasting the spread, recoveries, and deaths from the current outbreak of COVID-19 (28).

(ii) The government must increase the capacity of intensive care units equipped with ventilators and related equipment. At present, only 1,500 ventilators are available throughout the country, which is not enough to cope with the emergent situation. Similarly, only one doctor is available for every 1,720 patients. This overburdens doctors who are treating COVID-19 patients in addition to their normal patients.

\section{REFERENCES}

1. Li Q, Guan X, Wu P, Wang X, Zhou L, Tong Y, et al. Early transmission dynamics in Wuhan, China, of novel coronavirus-infected pneumonia. $N$ Engl J Med. (2020) 382:1199-207. doi: 10.1056/NEJMoa2001316

2. Huang C, Wang Y, Li X, Ren L, Zhao J, Hu Y, et al. Clinical features of patients infected with 2019 novel coronavirus in Wuhan, China. Lancet. (2020) 395:497-506. doi: 10.1016/S0140-6736(20)30183-5 (iii) There is a need to develop consensus-based national standard operating procedures (SOPs) to control the COVID-19 situation following the guidelines of the World health organization (WHO) and Center of Disease Control (CDC).

(iv) A campaign should be launched to create more awareness among people regarding the use of face masks and hand wash (29), and avoiding close contact with infected people (30).

(v) The SOPs, recommended by the Government during the month of Ramadan and Eid, must be strictly followed (31).

(vi) Currently, only 20 biosafety laboratories are operational in Pakistan, and these have a testing capability of 60,000 tests per day. The existing number of biosafety containment level 3 laboratories (BSL-3) require an additional 15 laboratories in order to achieve a target of 100,000 tests daily.

(vii) The government must announce a price limit for corona vaccines for the private sector and it should be as low as possible. It may be pointed out that many developed countries have already fixed the price of the vaccine in their countries (32).

\section{CONCLUSION}

The virus will continue to spread all over the world till a vaccine is available for each individual. Experts believe that the virus may remain within us for many years. The human race has never experienced such a situation before. All countries of the world should unite to adopt a common strategy under the umbrella of the United Nations platform to control the disease. We must create awareness among people to observe social distancing and lockdowns and wear face (in areas of high prevalence). Serious efforts should be made at the government level without any delay to acquire vaccines and make them available to each person.

\section{AUTHOR CONTRIBUTIONS}

The topic was devised by KK under the conceptualization and supervision of AA. KK used PubMed for literature review. All authors have read and agreed to the published final version.

\section{ACKNOWLEDGMENTS}

We are grateful to Professor Dr. Muhammad Ashfaq Ahmed for providing feedback on the review article.

3. Sahin A-R, Erdogan A, Agaoglu P-M, Dineri Y, Cakirci A-Y, Senel M-E, et al. Novel coronavirus (COVID-19) outbreak: a review of the current literature. Eurasian J Med Oncol. (2020) 4:1-7. doi: 10.14744/ejmo.2020.1 2220

4. Moore KC. Readapting pandemic premediation and propaganda: soderbergh's contagion amid COVID-19. Arts. (2020) 9:112. doi: 10.3390/arts9040112

5. Government of Pakistan. Coronavirus in Pakistan. (2020). Available online at: http://www.covid.gov.pk (accessed March 30, 2021). 
6. Mubeen SM, Kamal S, Kamal S, Balkhi F. Knowledge and awareness regarding spread and prevention of COVID-19 among the young adults of Karachi. $J$ Pakistan Med Assoc. (2020) 70:S169-74. doi: 10.5455/JPMA.40

7. Abid K, Bari YA, Younas M, Tahir Javaid S, Imran A. Progress of COVID-19 epidemic in Pakistan. Asia Pacific $J$ Public Health. (2020) 32:154-6. doi: 10.1177/10105395209 27259

8. The News. WHO Warns Pakistan's COVID-19 Cases Can Surge to 200,000 by Mid July. (2020). Available online at: https://www.thenews.com.pk/latest/ 648722-who-warns-pakistans-covid-19-cases-can-surge-to-200000-bymid-july (accessed July 12, 2021).

9. Volz E, Mishra S, Chand M, Barrett JC, Johnson R, Geidelberg $\mathrm{L}$, et al. Transmission of SARS-CoV-2 Lineage B. 1.1. 7 in England: insights from linking epidemiological and genetic data. medRxiv. (2021) 2021:20249034. doi: 10.1101/2020.12.30.202 49034

10. Umair M, Ikram A, Salman M, Alam MM, Badar N, Rehman Z, et al. Importation of SARS-CoV-2 variant B. 117 in Pakistan. J Med Virol. (2021) 93:2623-5. doi: 10.1002/jmv.26869

11. Mallhi TH, Ahmad A, Butt MH, Misbah S, Khan YH, Alotaibi NH. Chloroquine and hydroxychloroquine in COVID-19: Practice implications for healthcare professionals. J Coll Phys Surg Pakistan. (2020) 30:12428. doi: 10.29271/jcpsp.2020.Supp2.124

12. Ahmed $\mathrm{K}$, Shahid $\mathrm{S}$, Nawaz N. Impacts of climate variability and change on seasonal drought characteristics of Pakistan. Atmos Res. (2018) 214:36474. doi: 10.1016/j.atmosres.2018.08.020

13. Callaway E. Outrage over Russia's fast-track coronavirus vaccine. Nature. (2020) 584:334-5. doi: 10.1038/d41586-020-02386-2

14. The Express Tribune. "Good news:" Pakistan Secures $17 \mathrm{~m}$ Doses of AstraZeneca Vaccine. (2021). Available online at: https://tribune.com.pk/ story/2282011/good-news-pakistan-secures-17m-doses-of-astrazenecavaccine (accessed July 20, 2021).

15. Gallup Survery Pakistan. Gallup Pakistan COVID-19 Related Research Series. (2021). Available online at: https:www.//gallup.com.pk/post/30779 (accessed April 14, 2021).

16. Selva KJ, van de Sandt CE, Lemke MM, Lee CY, Shoffner SK, Chua BY, et al. Systems serology detects functionally distinct coronavirus antibody features in children and elderly. Nat Commun. (2021) 12:114. doi: 10.1038/s41467-021-22236-7

17. Camporota L, Meadows C, Ledot S, Scott I, Harvey C, Garcia M, et al. Consensus on the referral and admission of patients with severe respiratory failure to the NHS ECMO service. Lancet Respirat Med. (2021) 9:e167. doi: 10.1016/S2213-2600(20)30581-6

18. Anser MK, Yousaf Z, Khan MA, Nassani AA, Abro MMQ, Vo XH, et al. Social and administrative issues related to the COVID-19 pandemic in Pakistan: better late than never. Environ Sci Poll Res. (2020) 27:3456773. doi: 10.1007/s11356-020-10008-7

19. Javed B, Sarwer A, Soto EB. Perspectives T. Is Pakistan on track to have COVID-19 transmission and mortality rates similar to those of Italy, Iran or the USA? Drug Therapy Perspect. (2020) 36:2937. doi: 10.1007/s40267-020-00726-w

20. Shulla K, Voigt B-F, Cibian S, Scandone G, Martinez E, Nelkovski F, et al. Effects of COVID-19 on the sustainable development goals (SDGs). Disc Sustainabil. (2021) 2:1-19. doi: 10.1007/s43621-021-00026-x
21. Mukarram M. Impact of COVID-19 on the UN sustainable development goals (SDGs). Strategic Anal. (2020) 44:253-8. doi: 10.1080/09700161.2020.1788363

22. Giritli Nygren K, Olofsson AJ. Managing the Covid-19 pandemic through individual responsibility: the consequences of a world risk society and enhanced ethopolitics. J Risk Res. (2020) 23:1031-5. doi: 10.1080/13669877.2020.1756382

23. Mills EC, Savage E, Lieder J. Chiu ES. Telemedicine and the COVID19 pandemic: are we ready to go live? Adv Skin Wound Care. (2020) 57:462. doi: 10.1097/01.ASW.0000669916.01793.93

24. Drogin EY. Forensic mental telehealth assessment (FMTA) in the context of COVID-19. Int J Law Psychiatry. (2020) 71:101595. doi: 10.1016/j.ijlp.2020.101595

25. Zakeri MA, Dehghan M. The impact of the COVID-19 disease on the referral and admission of the non-COVID-19 patients. Int J Health Plann Manage. (2021) 36:209-11. doi: 10.1002/hpm.3060

26. Martínez-Sanz J, Pérez-Molina JA, Moreno S, Zamora J, SerranoVillar S. Understanding clinical decision-making during the COVID-19 pandemic: a cross-sectional worldwide survey. EClinicalMedicine. (2020) 27:100539. doi: 10.1016/j.eclinm.2020.100539

27. Qian X, Ren R, Wang Y, Guo Y, Fang J, Wu Z-D, et al. Fighting against the common enemy of COVID-19: a practice of building a community with a shared future for mankind. Infect Dis Poverty. (2020) 9:1-6. doi: 10.1186/s40249-020-00650-1

28. Ali M, Khan DM, Aamir M, Khalil U, Khan Z. Forecasting COVID-19 in Pakistan. PLoS ONE. (2020) 15:e0242762. doi: 10.1371/journal.pone.0242762

29. Li T, Liu Y, Li M, Qian X, Dai SY. Mask or no mask for COVID-19: a public health and market study. PLoS ONE. (2020) 15:e0237691. doi: 10.1371/journal.pone.0237691

30. Cirrincione L, Plescia F, Ledda C, Rapisarda V, Martorana D, Moldovan RE, et al. COVID-19 pandemic: prevention and protection measures to be adopted at the workplace. Sustainability. (2020) 12:3603. doi: 10.3390/su12093603

31. Malik S. Knowledge of COVID-19 symptoms and prevention among Pakistani adults: a cross-sectional descriptive study. Rawal Med J. (2020) 45:7869. doi: 10.31234/osf.io/wakmz

32. Dyer O. Covid-19: countries are learning what others paid for vaccines. $\mathrm{Br}$ Med J. (2021) 372:n281. doi: 10.1136/bmj.n281

Conflict of Interest: The authors declare that the research was conducted in the absence of any commercial or financial relationships that could be construed as a potential conflict of interest.

Publisher's Note: All claims expressed in this article are solely those of the authors and do not necessarily represent those of their affiliated organizations, or those of the publisher, the editors and the reviewers. Any product that may be evaluated in this article, or claim that may be made by its manufacturer, is not guaranteed or endorsed by the publisher.

Copyright (c) 2021 Kamran and Ali. This is an open-access article distributed under the terms of the Creative Commons Attribution License (CC BY). The use, distribution or reproduction in other forums is permitted, provided the original author(s) and the copyright owner(s) are credited and that the original publication in this journal is cited, in accordance with accepted academic practice. No use, distribution or reproduction is permitted which does not comply with these terms. 